\title{
Hydrogen atom versus hydride transfer in cytochrome P450 oxidations: A combined mass spectrometry and computational study
}

\author{
Fabián G. Cantú Reinhard, ${ }^{[a]}$ Simonetta Fornarini, ${ }^{*[b]}$ Maria Elisa Crestoni, ${ }^{*[b]}$ and Sam P. de Visser ${ }^{*[a]}$
}

Abstract: Biomimetic models of short-lived enzymatic reaction intermediates can give useful insight into the properties and coordination chemistry of transition metal complexes. In this work we investigate a high-valent iron(IV)-oxo porphyrin cation radical complex, namely $\left[\mathrm{Fe}^{\mathrm{IV}}(\mathrm{O})\left(\mathrm{TPFPP}^{+*}\right)\right]^{+}$where TPFPP is the dianion of 5,10,15,20-tetrakis(pentafluorophenyl) porphyrin. The $\left[\mathrm{Fe}^{\mathrm{IV}}(\mathrm{O})\left(\mathrm{TPFPP}^{+*}\right)\right]^{+}$ion was studied by ion-molecule reactions in a Fourier transform-ion cyclotron resonance mass spectrometer through reactivities with 1,3,5-cycloheptatriene, 1,3-cyclohexadiene and toluene. The different substrates give dramatic changes in reaction mechanism and efficiencies, whereby cycloheptatriene leads to hydride transfer, while cyclohexadiene and toluene react via hydrogen atom abstraction. Detailed computational studies point to major differences in ionization energy as well as $\mathrm{C}-\mathrm{H}$ bond energies of the substrates that influence the hydrogen atom abstraction versus electron transfer pathways. The various variables that determine the pathways for hydride transfer versus hydrogen atom transfer are elucidated and discussed.

\section{Introduction}

Cytochrome P450 enzymes are versatile catalysts in the human body that detoxify the liver from foreign compounds, such as drugs and some of their metabolites as well as other xenobiotics. ${ }^{[1]}$ Structurally, the P450s contain an iron(III)-heme deeply embedded into a protein matrix, where the substrate binds into a pocket of varying size depending on the P450 isozyme. ${ }^{[2]}$ The P450 catalytic cycle uses molecular oxygen, two reduction and two protonation equivalents in order to convert the iron(III)-heme(water) resting state into its active form, namely the high-valent iron(IV)-oxo porphyrin cation radical species called Compound I (Cpdl) ${ }^{[3]}$ Cpdl is known as one of the most efficient and versatile oxidants in Nature and generally reacts with substrates through oxygen atom transfer. For instance, it converts aliphatic groups through a hydroxylation process into alcohols, but also can activate aromatic $\mathrm{C}-\mathrm{H}$ bonds into phenols and sulfides into sulfoxides. ${ }^{[1,4]}$ In particular, substrate

[a] F.G. Cantú Reinhard, Dr S.P. de Visser

Manchester Institute of Biotechnology and School of Chemical Engineering and Analytical Science

The University of Manchester, 131 Princess Street, Manchester M1 7DN, United Kingdom

sam.devisser@manchester.ac.uk

[b] Prof. Dr. S. Fornarini, Prof. Dr. M.E. Creston Dipartimento di Chimica e Tecnologie del Farmaco, Università di Roma "La Sapienza", P.le A. Moro 5, 00185, Roma, Italy mariaelisa.crestoni@uniroma1.it; simonetta.fornarini@uniroma1.it

Supporting information for this article is given via a link at the end of the document. hydroxylation has been the topic of many studies and controversies have been posed whether it is initiated by a ratedetermining hydrogen atom abstraction (HAT) or a hydride transfer $(\mathrm{HT})$, as explained in Scheme $1^{[5]}$

Thus, computational modelling on hydrogen atom abstraction reactions by $\mathrm{P} 450$ enzymes with common aliphatic substrates, such as alkanes or alkylbenzenes, revealed a stepwise mechanism with an initial hydrogen atom abstraction followed by radical rebound to form alcohol product complexes. ${ }^{[6]}$ However, experimental studies of a synthetic iron(IV)-oxo porphyrin in a reaction with the substrate 10-methyl-9,10-dihydroacridine $\left(\mathrm{AcrH}_{2}\right)$ gave hydride transfer instead. ${ }^{[7]}$ Computational modelling on these reaction mechanisms implicated that hydride and hydrogen atom transfer pathways could both be feasible under certain reaction conditions, but are determined by the thermochemical properties of the oxidants, intermediates and substrates. ${ }^{[8]}$ To gain more insight into the mechanisms leading to hydride transfer by $\mathrm{Cpdl}$ of P450, we pursued a combined mass spectrometry and computational study on the hydride versus hydrogen atom abstraction patterns of model substrates.

In particular, we compare the reactivity patterns of these $\mathrm{Cpd}$ models with substrates that are known-likely to react via either hydride or hydrogen atom transfer. Thus, 1,3,5-cycloheptatriene (CHT) is used as a model substrate for hydride transfer reactions and 1,3-cyclohexadiene (CHD) and toluene are investigated considered for aliphatic hydrogen atom transfer. We present here a detailed joint mass spectrometric and computational study on substrate activation by a synthetic $\mathrm{Cpdl}$ model and establish the origin of hydride versus hydrogen atom transfer pathways. Furthermore, a detailed thermochemical and valence bond analysis explains the intrinsic properties of substrate and oxidant that determine hydride transfer versus hydrogen atom transfer by metal-oxo oxidants.

\section{Results}

Mass spectrometry results.

The preparation of a high-valent iron(IV)-oxo porphyrin cation radical complex, $\left[\mathrm{Fe}^{\mathrm{IV}}(\mathrm{O})\left(\mathrm{TPFPP}^{+*}\right)\right]^{+}$with TPFPP being the dianion of 5,10,15,20-tetrakis(pentafluorophenyl) porphyrin, was done by treatment of [Fe ${ }^{\text {III }}$ (TPFPP)]Cl with iodosylbenzene as oxygen atom donor, in a methanol/dichloromethane solution at $40^{\circ} \mathrm{C}$ as previously reported. ${ }^{[9]}$ The reaction mixture sampled by electrospray ionization (ESI) and characterized by high resolution Fourier transform-ion cyclotron resonance (FT-ICR) mass spectrometry contains substantial amounts of an ion cluster centered at $\mathrm{m} / \mathrm{z} 1044.0116$, revealing the incorporation of one oxygen atom by the reactant species [Fe"I (TPFPP) $]^{+}$. When trapped in the FT-ICR cell, the mass-selected ions with $\mathrm{m} / \mathrm{z}$ 1044.0116 are remarkably stable toward unimolecular dissociation ( $k_{\text {diss }} \leq 0.001 \mathrm{~s}^{-1}$ ) and their fragmentation patterns and isotope patterns characterize them as $\left[\mathrm{Fe}^{\mathrm{IV}}(\mathrm{O})\left(\mathrm{TPFPP}^{+*}\right)\right]^{+}$. 


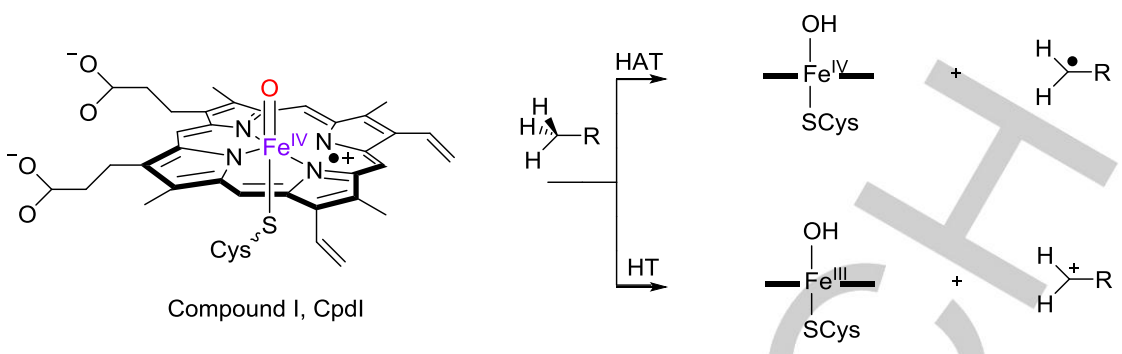

Scheme 1. Products obtained from a reaction of Cpdl with an aliphatic group.

Table 1. Thermodynamic ad-and kinetic data and product distributions for the reaction of selected hydrocarbons with $\left[\mathrm{Fe}^{\mathrm{IV}}(\mathrm{O})\left(\mathrm{TPFPP}^{++}\right)\right]^{+}$.

\begin{tabular}{|c|c|c|c|c|c|c|c|c|}
\hline Compound (A) & $\mathrm{IE}^{[\mathrm{a}]}$ & $\mathrm{BDE}_{\mathrm{CH}}{ }^{[b]}$ & $\mathrm{IE}_{\text {radical }}{ }^{[\mathrm{a}]}$ & $k_{\exp }^{[c]}$ & $\Phi(\%)$ & $\%[\mathrm{~A}-\mathrm{H}]^{+[\mathrm{d}]}$ & $\%\left[\mathrm{Fe}^{\mathrm{III}}(\mathrm{TPFPP})\right]^{+}$ & $\% A D D$ \\
\hline Toluene & 8.828 & 87.9 & $7.242^{[e]}$ & 0.36 & $3.1 \underline{9}^{[\mathrm{h}]}$ & - & 80 & 20 \\
\hline $\mathrm{CHT}$ & $8.0-8.3$ & 72.9 & $6.28^{[\text {[] }}$ & 2.67 & 30 & 40 & 60 & - \\
\hline $\mathrm{CHD}$ & 8.25 & 72.9 & $6.82^{[9]}$ & 1.58 & $17^{[\mathrm{H}]}$ & - & 100 & - \\
\hline
\end{tabular}

[a] In eV. [b] In kcal mol ${ }^{-1}$. [c] Second-order rate constant in units of $10^{-10} \mathrm{~cm}^{3}$ molecule $\mathrm{s}^{-1}$, at the temperature of the FT-ICR cell of $300 \mathrm{~K}$. [d] product ion at $\mathrm{m} / \mathrm{z}$ value for substrate minus $\mathrm{H}^{-}$. [e] Data from Ref. 13. [f] The reaction of cycloheptatriene-7-[ $\left.\mathrm{D}_{1}\right]$ displays a $\mathrm{H} / \mathrm{D}$ kinetic isotope effect of 2.5, resulting from the time independent ratio of the abundances of the $\mathrm{C}_{7} \mathrm{H}_{6} \mathrm{D}^{+}$and $\mathrm{C}_{7} \mathrm{H}_{7}{ }^{+}$product ions. [g] Data from Ref. 16. [h] Data from Ref. 112. [i] Data from Ref. 11.
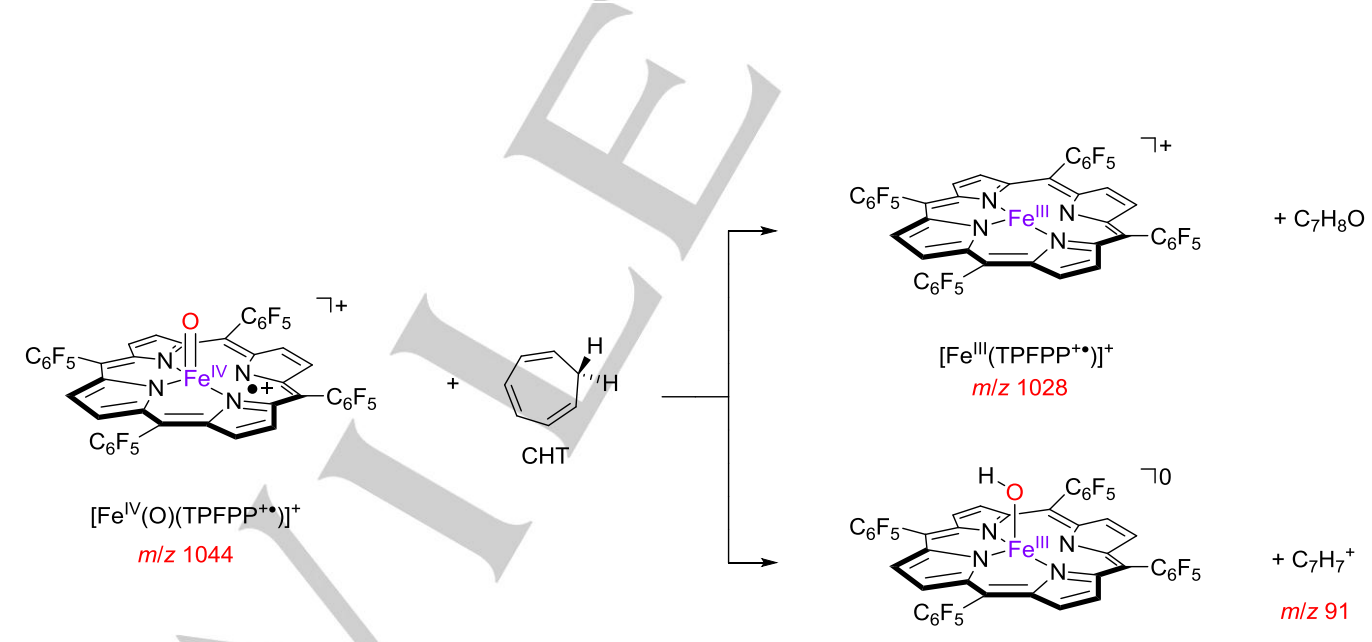

$\left[\mathrm{Fe}^{\mathrm{III}}(\mathrm{OH})(\mathrm{TPFPP})\right]^{0}$

Scheme 2. Reaction channels observed for the reaction of $\left[\mathrm{Fe}^{\mathrm{IV}}(\mathrm{O})\left(\mathrm{TPFPP}^{+}\right)\right]^{+}$with 1,3,5-cycloheptatriene in the FT-ICR cell. 
Moreover, when exposed to stationary concentrations of candidate reductants, they react with a wide variety of compounds, including $\mathrm{NO}, \mathrm{NO}_{2}$, aromatics, olefins, sulfides, amines, and phosphites. ${ }^{[10]}$

A comprehensive combined mass spectrometric and computational approach recently succeeded in unveiling the full details of multiple reaction channels and product distribution in olefin epoxidation, ${ }^{[11]}$ and aromatic hydroxylation, ${ }^{[12]}$ in the gasphase, i.e. in a solvent-free environment. In this context, we have become keenly interested in gaining further information on the Compound I-like reactivity of $\left[\mathrm{Fe}^{\mathrm{IV}}(\mathrm{O})\left(\mathrm{TPFPP}^{+*}\right)\right]^{+}$with $\mathrm{CHT}$, that has been assessed and is described herein. $\mathrm{CHT}$ is an isomer of toluene, although it lacks aromatic stabilization. Therefore, the two compounds possess quite different physical and chemical properties. In particular, $\mathrm{CHT}$ is characterized by a markedly lower ionization energy (IE): $8.0-8.3 \mathrm{eV}$ for $\mathrm{CHT}$ versus $8.828 \mathrm{eV}$ for toluene. ${ }^{[13]}$ Also significantly smaller for $\mathrm{CHT}$ versus toluene is its $\mathrm{C}-\mathrm{H}$ bond dissociation energy $\left(\mathrm{BDE}_{\mathrm{CH}}\right)$ for removal of a hydrogen atom from the methylene group. Thus, the $\mathrm{BDE}_{\mathrm{CH}}$ of methylene $\mathrm{C}-\mathrm{H}$ bond of $\mathrm{CHT}$ is $72.9 \mathrm{kcal} \mathrm{mol}^{-1}$ whereas it is $87.9 \mathrm{kcal} \mathrm{mol}^{-1}$ for the cleavage of the $\mathrm{H}_{-}-\mathrm{CH}_{2} \mathrm{C}_{6} \mathrm{H}_{5}$ bond in toluene. ${ }^{[14]}$ However, the most notable reactivity feature in the reactive behavior of $\mathrm{CHT}$ is the drive towards formation of $\mathrm{c}-\mathrm{C}_{7} \mathrm{H}_{7}{ }^{+}$, i.e. the tropylium ion, which has aromatic character and hence is relatively stable. This species plays an important role in the oxidation of $\mathrm{CHT}$ and $\mathrm{CHT}$-derivatives and the process has interesting synthetic applications, namely in anodic oxidation, oxidation by photoinduced electron transfer, and chemoenzymatic studies. ${ }^{[15]}$

Because of the peculiar features of cycloheptatriene, we envisaged a detailed gas phase reactivity study towards $\left[\mathrm{Fe}^{\mathrm{IV}}(\mathrm{O})\left(\mathrm{TPFPP}^{+*}\right)\right]^{+}$would be interesting and could contribute to elucidation of the intrinsic factors that determine the reactivity behavior of this model of $\mathrm{P} 450 \mathrm{Cpd} \mathrm{I}$. An interesting comparison may as well arise from the reaction of $\left[\mathrm{Fe}^{\mathrm{IV}}(\mathrm{O})\left(\mathrm{TPFPP}^{+\cdot}\right)\right]^{+}$with 1,3-cyclohexadiene (CHD) as it has a comparable IE and also similar $\mathrm{C}-\mathrm{H} \mathrm{BDE}_{\mathrm{CH}}$ for the methylene group (IE and $\mathrm{BDE}_{\mathrm{CH}}$ values are equal to $8.25 \mathrm{eV}$ and $72.9 \mathrm{kcal} \mathrm{mol}^{-1}$, respectively), see Table $1 .^{[13,14,16]}$ However, ionization of the so-formed radical

is remarkably easier for $\mathrm{C}_{-} \mathrm{C}_{7} \mathrm{H}_{7}{ }^{\circ}$ when compared to the $\mathrm{c}-\mathrm{C}_{6} \mathrm{H}_{7}$. radical from 1,3-cyclohexadiene (6.28 vs. $6.82 \mathrm{eV}$, respectively). Table 1 gives a summary of all cited thermochemical data. ${ }^{[13,14,16]}$ The thermal reactivity of $\left[\mathrm{Fe}^{\mathrm{IV}}(\mathrm{O})\left(\mathrm{TPFPP}^{+*}\right)\right]^{+}$towards $\mathrm{CHT}$ occurs along two reaction channels, namely a process that yields the reduced $\left[\mathrm{Fe}^{\text {III }}(\mathrm{TPFPP})\right]^{+}$ion and oxidized (neutral) substrate, and a formal hydride transfer (HT) pathway, whereby $\mathrm{C}_{7} \mathrm{H}_{7}{ }^{+}$as ionic product is released together with (neutral) [Fe"'(OH)(TPFPP)], Scheme 2. Thus, upon isolation of the ion at $\mathrm{m} / \mathrm{z} 1044$ representing the $\left[\mathrm{Fe}^{\mathrm{IV}}(\mathrm{O})\left(\mathrm{TPFPP}^{+*}\right)\right]^{+}$complex, ion abundances were measured as a function of time in the presence of a stationary concentration of $\mathrm{CHT}$. Indeed, the abundance of ions at $\mathrm{m} / \mathrm{z} 1044$ decayed as a function of time and two new peaks in the spectrum appeared at $\mathrm{m} / \mathrm{z} 1028$ and $\mathrm{m} / \mathrm{z}$ 91. These two peaks correspond to the products $\left[\mathrm{Fe}^{\text {III }} \text { (TPFPP) }\right]^{+}$and $\mathrm{C}_{7} \mathrm{H}_{7}^{+}$resulting from oxygen atom transfer and hydride transfer from the reaction of $\left[\mathrm{Fe}^{\mathrm{IV}}(\mathrm{O})\left(\mathrm{TPFPP}^{+*}\right)\right]^{+}$ with cycloheptatriene. The reaction is fast and characterized by a reaction efficiency of $\Phi=30 \%$ (see Table 1). Semi-logarithmic plots of the reactant ion abundance as a function of time obtained at varying $\mathrm{CHT}$ concentration enabled us to calculate the second-order rate constants for both reaction processes, as displayed in Figure $S 1$ in the Supporting Information.

The reaction of $\left[\mathrm{Fe}^{\mathrm{IV}}(\mathrm{O})\left(\mathrm{TPFPP}^{+*}\right)\right]^{+}$with cycloheptatriene-7-[ $\left.\mathrm{D}_{1}\right]$ gives a mixture of hydrogen and deuterium transfer and results in the formation of both $\mathrm{C}_{7} \mathrm{H}_{6} \mathrm{D}^{+}$and $\mathrm{C}_{7} \mathrm{H}_{7}{ }^{+}$ions in the product mixture. The abundance ratio of $\mathrm{C}_{7} \mathrm{H}_{6} \mathrm{D}^{+}$and $\mathrm{C}_{7} \mathrm{H}_{7}{ }^{+}$product ions is about 2.5 and is independent of the reaction time. Therefore, the ratio of the abundances of $\mathrm{C}_{7} \mathrm{H}_{6} \mathrm{D}^{+}$versus $\mathrm{C}_{7} \mathrm{H}_{7}{ }^{+}$corresponds to the $\mathrm{H} / \mathrm{D}$ kinetic isotope effect for competing hydride versus deuteride abstraction from cycloheptatriene-7-[D $\left[D_{1}\right]$. The kinetic plot for the reaction of $\left[\mathrm{Fe}^{\mathrm{IV}}(\mathrm{O})\left(\mathrm{TPFPP}^{+*}\right)\right]^{+}$with cycloheptatriene$7-\left[D_{1}\right]$ is given in Figure 1 showing the profiles of ion abundances as a function of time.

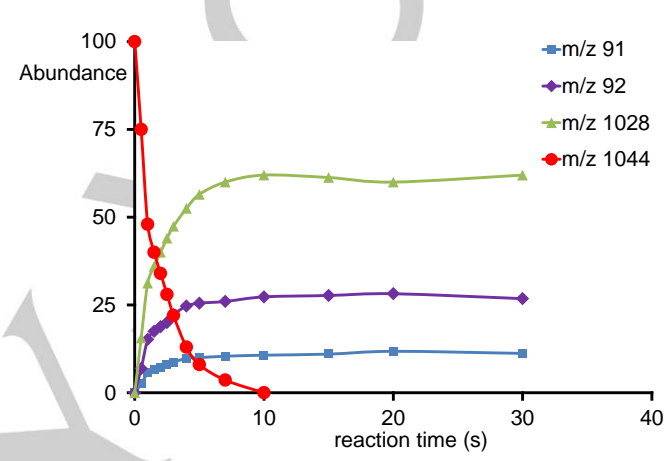

Figure 1. Ion abundances as a function of time after isolation of $\mathrm{m} / \mathrm{z} 1044$ ions, i.e. $\left[\mathrm{Fe}^{\mathrm{IV}}(\mathrm{O})\left(\mathrm{TPFPP}^{+}\right)\right]^{+}$, in the FT-ICR cell in the presence of $5 \times 10^{-8} \mathrm{mbar}$ cycloheptatriene-7-[D $\left.\mathrm{D}_{1}\right]$ at room temperature.

It is interesting to note that the HT path is specific for $\mathrm{CHT}$, while formation of the reduced [Fe $\left.{ }^{\text {III }}(\mathrm{TPFPP})\right]^{+}$ion is commonly observed in the reactivity of both olefins and aromatic compounds. ${ }^{[1,12]}$ In order to find out how the reactivity of $\left[\mathrm{Fe}^{\mathrm{IV}}(\mathrm{O})\left(\mathrm{TPFPP}^{+*}\right)\right]^{+}$with $\mathrm{CHT}$ differs to that with aliphatic substrates, we decided to investigate-compare the reactivity of $\left[\mathrm{Fe}^{\mathrm{IV}}(\mathrm{O})\left(\mathrm{TPFPP}^{+*}\right)\right]^{+}$with CHD and toluene. Thus, P450 Cpd I models typically react with $\mathrm{CHD}$ through dehydrogenation and the formation of benzene, ${ }^{[17]}$ or alternatively by oxygen atom transfer to form the corresponding epoxide. On the other hand, using toluene as a substrate a mechanism was found starting with hydrogen atom abstraction and followed by $\mathrm{OH}$ rebound to form phenylmethanol products. ${ }^{[18]}$ As follows, the aromatic $\mathrm{C}_{7} \mathrm{H}_{8}$ isomer of $\mathrm{CHT}$, namely toluene, displays exclusive formation of the reduced $\left[\mathrm{Fe}^{\text {III }} \text { (TPFPP) }\right]^{+}$ion with a markedly lower efficiency of only $3 \underline{4} \%$, which includes also a formal addition path leading to a complex at $\mathrm{m} / \mathrm{z}$ value corresponding to the sum of oxidant and substrate (ADD pathway), Table 1. Also 1,3-cyclohexadiene with conjugated double bonds, undergoes exclusively an oxygen atom transfer process (OAT) with $17 \%$ efficiency, which could implicate substrate epoxidation. ${ }^{[11]}$ Thus, in aromatic hydroxylation and double pond epoxidation reactions studied for analogous systems, ${ }^{[11,12,191]}$ OAT is the common product ion, and hence would implicate epoxidation of CHD.
Commento [SM2]: Ref. 19 has been added, as suggested 


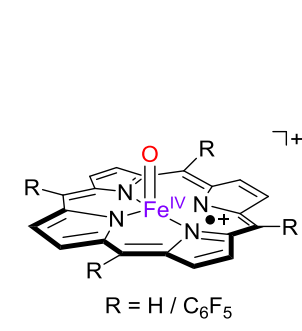

$\mathrm{R}=\mathrm{H}:\left[\mathrm{Fe}^{\mathrm{IV}}(\mathrm{O})\left(\mathrm{Por}^{+\bullet}\right)\right]^{+}$

$\mathrm{R}=\mathrm{C}_{6} \mathrm{~F}_{5}:\left[\mathrm{Fe}^{\mathrm{IV}}(\mathrm{O})\left(\mathrm{TPFPP}^{+\bullet}\right)\right]^{+}$
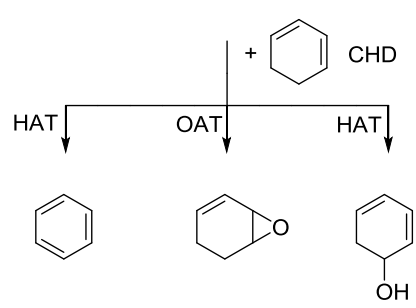
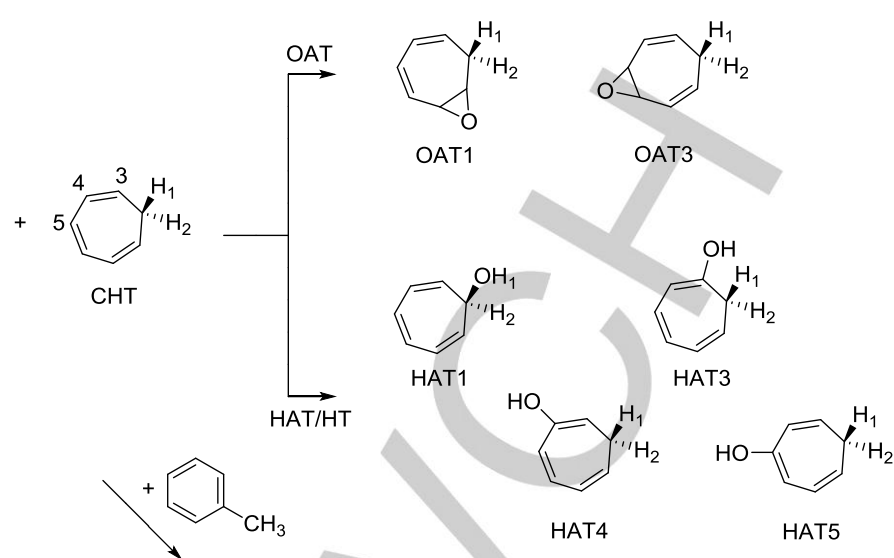

Scheme 3. Mechanisms considered in this work for the reactions of $\mathbf{1}$ and $\mathbf{2}$ with $\mathrm{CHT}, \mathrm{CHD}$ and toluene and the products obtained.

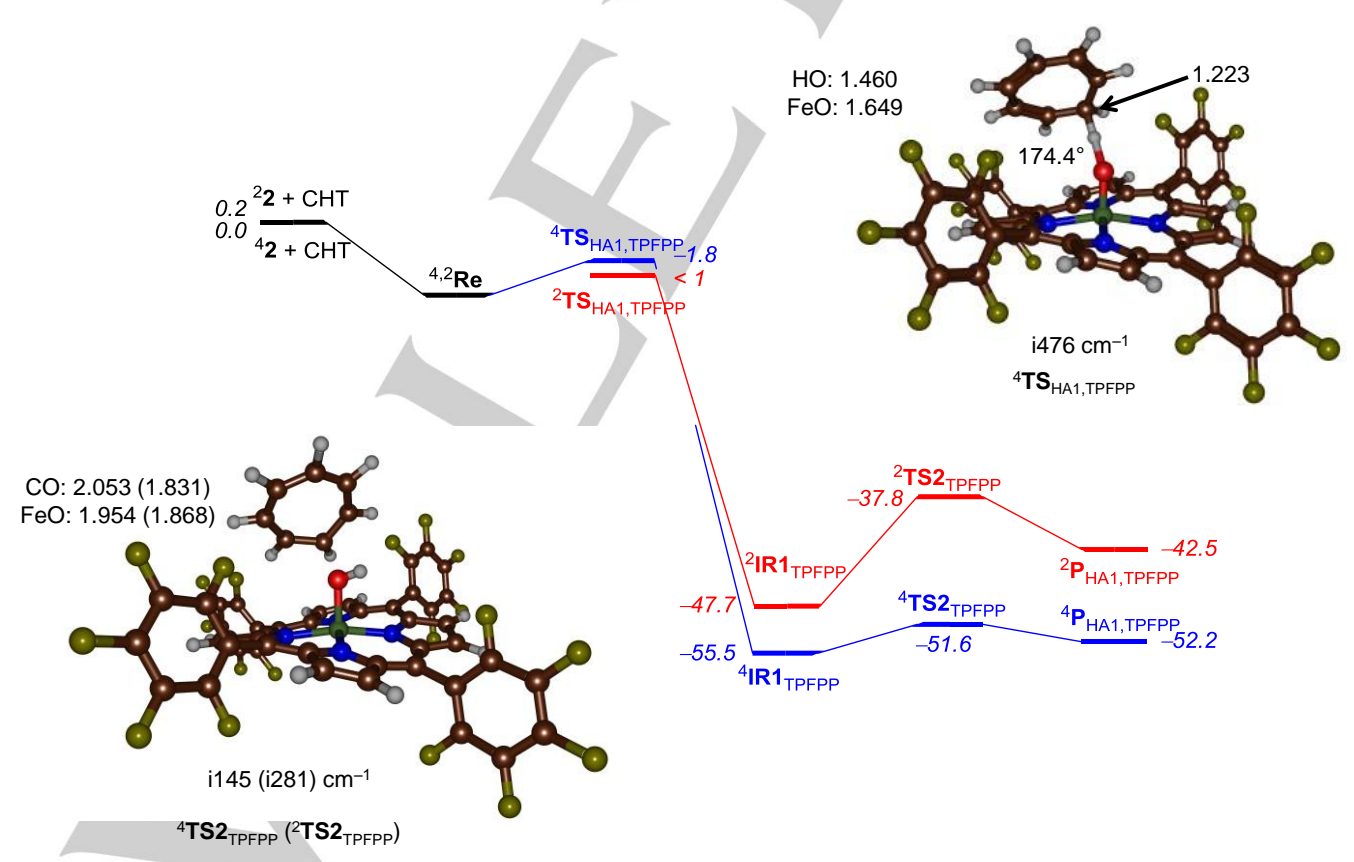

Figure 2. Free energy landscape for oxidation reactions of cycloheptatriene by ${ }^{4,2} \mathbf{2}$. Free energies use electronic energies at UB3LYP/BS2//UB3LYP/BS1 in kcal $\mathrm{mol}^{-1}$ and contain zero-point, entropic and thermal corrections to $298 \mathrm{~K}$. Also given are optimized geometries of ${ }^{4} \mathbf{T S}_{\mathrm{HA1}}$ and ${ }^{4,2} \mathbf{T S}^{-1} \mathbf{T P F P P}_{\mathrm{TP}}$ with bond lengths in angstroms, angles in degrees and the imaginary frequency in $\mathrm{cm}^{-1}$. 


\section{Computational modelling}

To support the experiments and gain insight into the reaction pathways for 1,3,5-cycloheptatriene activation by $\left[\mathrm{Fe}^{\mathrm{IV}}(\mathrm{O})\left(\mathrm{TPFPP}^{+\cdot}\right)\right]^{+}$we performed a computational study on the mechanisms and pathways leading to the various products for activation of $\mathrm{CHT}$. As a comparison, we also included computational studies using CHD and toluene as substrates, since the experimental studies with these substrates have considerably different product distributions (Table 1). Initial calculations using the CHT substrate utilized a TPFPP scaffold abbreviated to porphyrin (Por) without side chains, ${ }^{2,4} \mathbf{1}$. However in a second set of calculations the full system (TPFPP, ${ }^{2,4} \mathbf{2}$ ) was also studied for the full reaction pathway of the predominant hydroxylation reactions, on the quartet and doublet spin states (see Scheme 3). In the case of CHT substrate technically, oxygen atom transfer can lead to various isomeric epoxides, namely at positions 3 or 5 (Scheme 3 ) or alternatively a hydroxylation process can lead to alcohols from $\mathrm{H}_{1}, \mathrm{H}_{3}, \mathrm{H}_{4}$ and $\mathrm{H}_{5}$. Hydrogen atom abstraction from position $\mathrm{H}_{2}$ was also attempted but led to the same transition state and local minimum as the one from $H_{1}$. We decided to investigate all these mechanisms using established procedures reported recently. ${ }^{[11,12]}$

A detailed benchmark study aimed at reproducing experimental reaction free energies of activation of substrate sulfoxidation reactions by an iron(IV)-oxo species showed that PBE0 and B3LYP were the preferred density functional theory methods to reproduce experimental data and activation enthalpies to within $3-4 \mathrm{kcal} \mathrm{mol}^{-1}$ from experiment were obtained for a series of substrates. ${ }^{[20]}$ Furthermore, for several chemical systems we calculated bifurcation pathways and predicted the correct product distributions. For instance, we calculated the hydrogen atom abstraction pathways from the six possible hydrogen atoms of a proline residue in a peptide chain by prolyl-4hydroxylase and found a low-energy pathway for the formation of R-4-hydroxyproline, in agreement with experimental observation. ${ }^{[21]}$ Furthermore, for the cytochrome P450 peroxygenase reaction pathways were calculated for fatty acid decarboxylation and hydroxylation and the predicted product distributions matched experiment very well. ${ }^{[22]}$ As such we utilized these methods in this work

To gain further insight into hydride transfer versus hydrogen atom transfer pathways, we included calculations for the full mechanism of 1,3-cyclohexadiene and toluene, see Scheme 3. The full set of results is documented in the Supporting Information (Tables S1 - S16; Figures S2 - S10), while we focus on the main trends here. Note that hydride transfer is not always a feasible mechanism as will be discussed later; however, molecular orbital swaps were attempted in all cases to estimate the energy difference between hydrogen atom and hydride transfer pathways. Further details on the possibilities of hydride transfer follow in the thermochemical analysis of structures in the Discussion section.

Let us start with a description of a typical reaction mechanism of oxygen atom transfer, namely of cycloheptatriene activation at its methylene group by the iron(IV)-oxo model. In the following, we will add the label for the reaction process as a subscript to the molecule. Calculations were done starting from the isoelectronic doublet and quartet spin state structures of $\left[\mathrm{Fe}^{\mathrm{IV}}(\mathrm{O})\left(\mathrm{Por}^{+*}\right)\right]^{+},{ }^{4,2} \mathbf{1}$. Similarly to our previous work on this chemical system as well as reports on P450 Cpdl, ${ }^{[4 b, 12,23]}$ we find the doublet and quartet spin states of the reactant complex to be within $0.5 \mathrm{kcal} \mathrm{mol}^{-1}$ for ${ }^{4,2}\left[\mathrm{Fe}^{\mathrm{IV}}(\mathrm{O})\left(\mathrm{Por}^{+*}\right)\right]^{+}$as well as for ${ }^{4,2}\left[\mathrm{Fe}^{\mathrm{IV}}(\mathrm{O})\left(\mathrm{TPFPP}^{+\cdot}\right)\right]^{+:}{ }^{4,2} \mathbf{2}$.

Figure 2 gives the potential energy landscape for cycloheptatriene activation on one of the aliphatic $\mathrm{C}-\mathrm{H}$ bonds by 4,2 . The substrate and oxidant initially form a reactant complex $\left({ }^{4,2} \mathbf{R e}\right)$ and then react with a fast hydrogen atom abstraction leading to a very low-energy intermediate. Although the ${ }^{4} \mathbf{T S}_{\text {HA1,TPFPP }}$ barrier is lower in energy than isolated reactants, it is slightly higher in energy than the reactants complex. Therefore, the hydrogen atom abstraction will be fast. On the doublet spin state, we were unable to locate the structure of the hydrogen atom transition states as all attempts led to the product complexes instead. Similarly to previous calculations on aliphatic hydroxylation by P450 Cpdl, the doublet and quartet spin states are close in energy and only at the products stage they diverge due to differences in orbital occupation. ${ }^{[4 b, 66,24]}$

The group spin densities of ${ }^{4} \mathrm{TS}_{\mathrm{HA} 1, \mathrm{TPFPP}}$ give $\rho_{\mathrm{FeO}}=2.16, \rho_{\mathrm{TPFPP}}$ $=-0.06$ and $\rho$ SubH $=0.90$, which points to a hydrogen atom abstraction transition state coupled to a triplet spin iron(IV)-oxo group. Interestingly, the intermediate ( $\left.{ }^{4} \mathbf{R} \mathbf{1}_{\text {TPFPP }}\right)$ that connects to this transition state has spin densities corresponding to $\rho_{\mathrm{FeO}}=$ 2.96, $\rho_{\text {TPFPP }}=0.02$ and $\rho_{\text {Sub }}=0.02$, which implies that the intermediate is an ion-molecule complex of $\mathrm{C}_{7} \mathrm{H}_{7}{ }^{+}$with a neutral $[\mathrm{Fe}(\mathrm{OH})(\mathrm{TPFPP})]^{0}$ molecule. Therefore, the mechanism starts with a fast hydrogen atom abstraction, but en route to the intermediate another electron transfer takes place to form the overall hydride transfer intermediate ${ }^{4,2} \mathbf{I R 1}$. In the next stage of the reaction the $\mathrm{OH}^{-}$rebound gives alcohol product complexes (P) via the rebound transition state TS2. As can be seen from Figure 2, the rebound encounters a barrier of $3.9 \mathrm{kcal} \mathrm{mol}^{-1}$ in the quartet spin state, but $9.9 \mathrm{kcal} \mathrm{mol}^{-1}$ in the doublet spin state These barriers, particularly the one in the doublet spin state are relatively high and may implicate dissociation of the complex into individual $\mathrm{C}_{7} \mathrm{H}_{7}^{+}$and $[\mathrm{Fe}(\mathrm{OH})(\mathrm{TPFPP})]^{0}$. Indeed, the experimental measurements observed $\mathrm{C}_{7} \mathrm{H}_{7}{ }^{+}$products alongside the reduced complex [Fe(TPFPP) $]^{+}$. It could very well be that the latter is formed through the low-barrier high-spin reaction mechanism, whereas the low-spin mechanism leads to dissociation of the intermediate delivering free $\mathrm{C}_{7} \mathrm{H}_{7}{ }^{+}$ions. Apart from calculations on the full structure ${ }^{4,2} \mathbf{2}$ and its mechanism with substrates, we did a more comprehensive study using the smaller model ${ }^{4,2} \mathbf{1}$, whereby mechanisms for various hydrogen atom abstractions and oxygen atom transfer processes were investigated. In general, the hydrogen atom abstraction mechanism is the same for ${ }^{4,2} \mathbf{1}$ as compared to ${ }^{4,2} \boldsymbol{2}$. The ${ }^{4,2} \mathbf{T S}_{\text {HA1 }}$ barriers are relatively early on the potential energy surface with short $\mathrm{C}-\mathrm{H}$ and long $\mathrm{O}-\mathrm{H}$ bonds (1.189 and $1.143 \AA$ and 1.560 and $1.762 \AA$, respectively) indicative of a fast reaction process (see Figure 3). Although generally aliphatic hydroxylation mechanisms are stepwise via a radical intermediate; for the small model no stable radical and/or cationic intermediates could be located, which implies a fast and efficient rebound to alcohol products. Therefore, the small model is not good enough to mimic the experimental system. Further evidence that the small model fails to capture the chemical properties of the meso-substituents follows from the calculated bond dissociation energies $\left(\mathrm{BDE}_{\mathrm{OH}}\right)$ of the $\mathrm{O}-\mathrm{H}$ bond of the $\left[\mathrm{Fe}^{\mathrm{IV}}(\mathrm{OH})(\mathrm{Por})\right]^{+}$versus $\left[\mathrm{Fe}^{\mathrm{IV}}(\mathrm{OH})(\mathrm{TPFPP})\right]^{+}$complexes. 


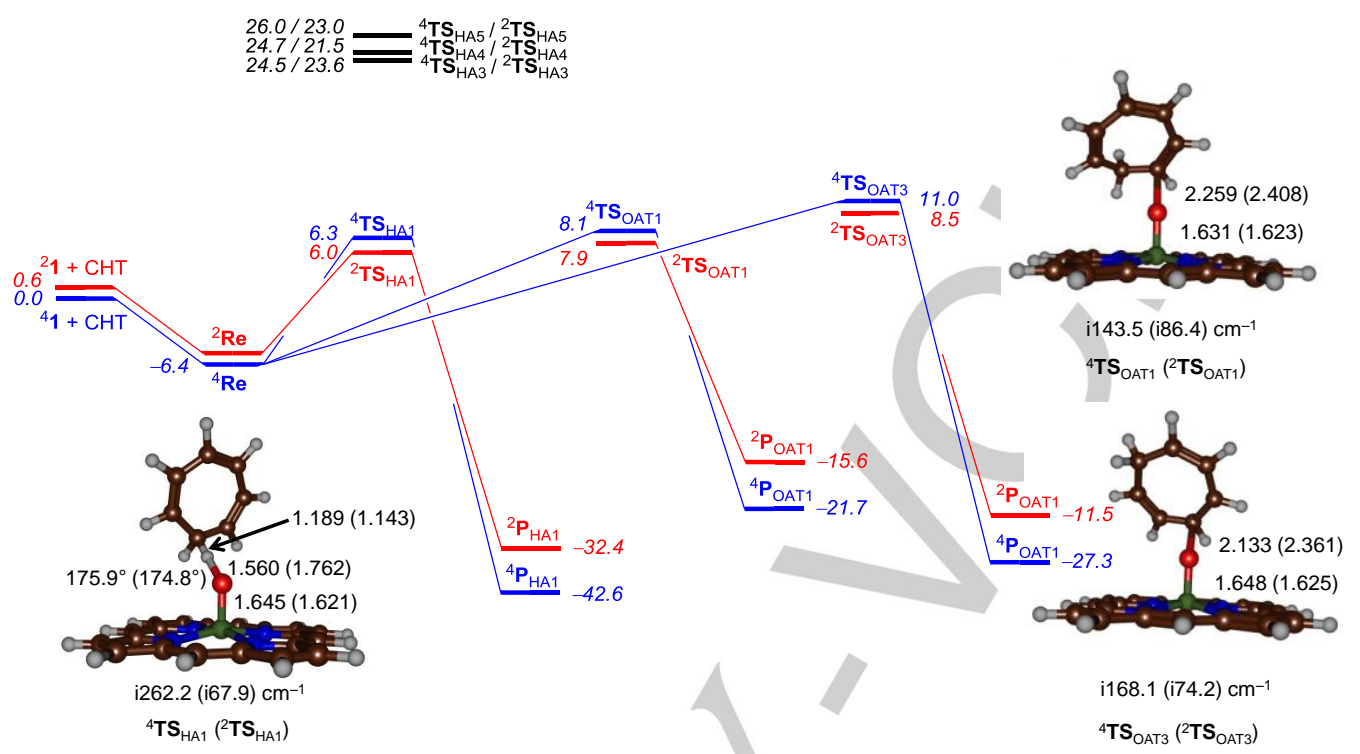

Figure 3. Free energy landscape for HAT and OAT reactions from cycloheptatriene by ${ }^{4,2} \mathbf{1}$. Free energies use electronic energies at UB3LYP/BS2//UB3LYP/BS1 in $\mathrm{kcal} \mathrm{mol}^{-1}$ and contain zero-point, entropic and thermal corrections. Also given are optimized geometries of ${ }^{4,2} \mathbf{T S}_{\mathrm{HAT} 1},{ }^{4,2} \mathbf{T S}_{\mathrm{OAT} 1}$ and ${ }^{4,2} \mathbf{T S}_{\mathrm{OAT3}}$ with bond lengths in angstroms, angles in degrees and the imaginary frequency in $\mathrm{cm}^{-1}$.

In particular, we calculate an energy difference between the iron(IV)-hydroxo and the sum of the iron(IV)-oxo porphyrin cation radical model and a hydrogen atom of $42.8 \mathrm{kcal} \mathrm{mol}^{-1}$ for $\left[\mathrm{Fe}^{\mathrm{IV}}(\mathrm{OH})(\mathrm{TPFPP})\right]^{+}$and $83.6 \mathrm{kcal} \mathrm{mol}^{-1}$ for $\left[\mathrm{Fe}^{\mathrm{IV}}(\mathrm{OH})(\mathrm{Por})\right]^{+}$. This difference results from a change of $8.0 \mathrm{kcal} \mathrm{mol}^{-1}$ in the electron affinity of the iron(IV)-oxo species and $32.2 \mathrm{kcal} \mathrm{mol}^{-1}$ drop in $\mathrm{pK}_{\mathrm{a}}$ value of the iron(IV)-hydroxo species. As a consequence of this, the small model reacts with larger exothermicity and smaller hydrogen atom abstraction barriers with substrates with aliphatic groups than the large system. The barriers for hydrogen atom abstraction for both the small and large models $\left({ }^{4,2} \mathbf{1}\right.$ and $\left.{ }^{4,2} \mathbf{2}\right)$ are relatively small. Previously, a series of hydrogen atom abstraction barriers with a range of aliphatic substrates showed early transition states to correspond to lower reaction barriers. ${ }^{[25]}$ Indeed, ${ }^{4,2} \mathbf{T S} \mathbf{H}_{\mathrm{HA} 1}$ are low in energy and only $\Delta \mathrm{G}^{\ddagger}=6.0 / 6.3 \mathrm{kcal} \mathrm{mol}^{-1}$ above the energy of reactants in the doublet/quartet spin state. Note also that the imaginary frequency in the transition state is relatively low (i262 $\mathrm{cm}^{-1}$ for ${ }^{4} \mathbf{T S}_{\mathrm{HA} 1}$ and $\mathrm{i} 476 \mathrm{~cm}^{-1}$ for ${ }^{4} \mathbf{T S}_{\mathrm{HA1}, \mathrm{TPFPP}}$ ). Typical values of the imaginary frequency for hydrogen atom abstraction barriers are well over i1500 $\mathrm{cm}^{-1}$, which usually leads to a major kinetic isotope effect (KIE) for the replacement of the transferring | hydrogen atom by deuterium. ${ }^{[26]}$ We cal

culate a value of $\mathrm{KIE}=2.7$, which matches the experimental rate constant ratio perfectly. Nevertheless, typical KIE values of hydrogen atom abstraction barriers are well above 10 for analogous systems. ${ }^{[27]}$

For all the smaller models dealing with ${ }^{4,2}\left[\mathrm{Fe}^{\mathrm{IV}}(\mathrm{O})\left(\mathrm{Por}^{+*}\right)\right]^{+}$, after passing the hydrogen atom abstraction transition states, the system directly collapses to the alcohol product complex and no stable radical intermediates could be located and hence a concerted hydroxylation process is predicted. In previous work on P450 model complexes, ${ }^{[4 b, 6,24,25]}$ most HAT pathways showed a shallow intermediate that was separated with a small barrier to products (typically less than $1 \mathrm{kcal} \mathrm{mol}^{-1}$ on the doublet spin state surface and less than $5 \mathrm{kcal} \mathrm{mol}^{-1}$ on the high-spin surface); however, no such local minimum could be located here and all attempts converged to the product complexes instead.

Therefore, the absence of a radical intermediate may have to do with the lack of meso-substituents in the model that affects the electron affinity and hydrogen atom abstraction ability of the complex as will be discussed in the thermochemical section later. The group-spin densities for the doublet and quartet intermediates give most radical character on the $\mathrm{FeO}$ group and virtually no spin density is seen on the substrate. Consequently, these intermediates correspond to a formal hydride transfer from substrate to oxidant. The reaction is highly exothermic and ${ }^{4,2} \mathbf{R} \mathbf{1}$ are below reactants by $\Delta \mathrm{G}=55.5$ (quartet) and 47.7 (doublet) $\mathrm{kcal} \mathrm{mol}^{-1}$. Clearly, the small model does not capture the properties of the intermediate state well even though the hydrogen atom abstraction barriers are similar in structure and electronic configuration.

In contrast to the intermediates ${ }^{4,2} \mathbf{I R 1}$, the hydrogen atom abstraction transition states have significant radical character on the substrate. To be specific, a spin density of $0.88(-0.73)$ is found on the $\mathrm{C}_{7} \mathrm{H}_{8}$ unit in ${ }^{4,2} \mathbf{T S}_{\mathrm{HA1}}$. Therefore, during the transition state a hydrogen atom is transferred, which is quickly followed by another electron transfer before reaching the intermediate state. The last step, then, refers to an $\mathrm{OH}^{-}$transfer
Commento [SM3]: This sentence is not very clear to us. It seems that the barrier to reach TS(HA1) is rather higher for the small system than for the TPFPP one. 


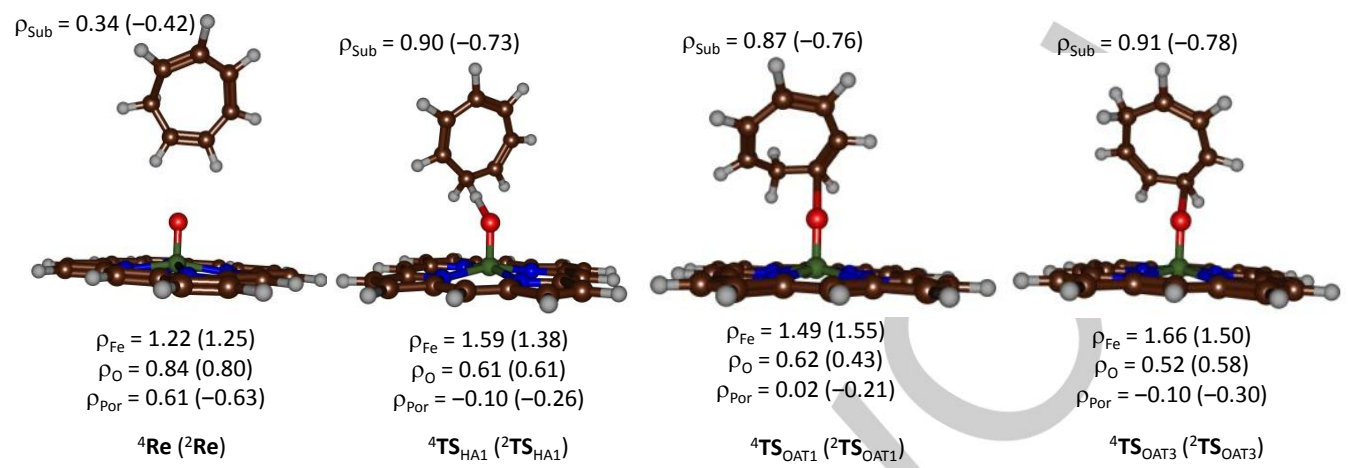

Figure 4. Group spin densities of reactant complexes and low-energy transition states for the reaction of $\left[\mathrm{Fe}^{\mathrm{IV}}(\mathrm{O})\left(\mathrm{Por}^{+*}\right)\right]^{+}$with $\mathrm{CHT}$ as calculated at UB3LYP/BS2//UB3LYP/BS1.

Subsequently, we calculated hydrogen atom abstraction by ${ }^{4,2} \boldsymbol{1}$ at position $\mathrm{H}_{3}, \mathrm{H}_{4}$ and $\mathrm{H}_{5}$ and the doublet and quartet barrier heights are given in Figure 3 as well. As follows, all these hydrogen atom abstraction barriers are well over $20 \mathrm{kcal} \mathrm{mol}^{-1}$ and will not be competitive with hydrogen atom abstraction from $\mathrm{H}_{1}$ or $\mathrm{H}_{2}$. This is not surprising as hydrogen atom abstraction from aromatic centers (or olefins) generally requires a lot of energy and does not give a stable radical. ${ }^{[28]}$

We then studied $\mathrm{C}-\mathrm{O}$ activation through an electrophilic attack of the oxo group onto the carbon atom at position 3 and 5 . Similarly to the aliphatic hydroxylation reported in Figure 3, the reaction is concerted with a $\mathrm{C}-\mathrm{O}$ bond formation barrier that directly leads to epoxide product complexes without the formation of a radical intermediate. The two pathways are competitive and only a small energy difference on the $\mathrm{C}-\mathrm{O}$ bond formation barrier is seen between attacks on position 3 versus 5 . Therefore, the oxygen atom transfer on position 3 and 5 will be competitive, although their barriers are higher in energy than that for aliphatic hydrogen atom abstraction. Similarly to the aliphatic hydroxylation barriers, also the oxygen atom transfer barriers are early on the potential energy surface with long $\mathrm{C}-\mathrm{O}$ and short $\mathrm{Fe}-\mathrm{O}$ distances (Figure 3).

Thereafter, we investigated the mechanistic landscapes for oxygen atom transfer of $\left[\mathrm{Fe}^{\mathrm{IV}}(\mathrm{O})\left(\mathrm{TPFPP}^{+*}\right)\right]^{+}$with toluene and 1,3-cyclohexadiene (CHD) on both spin states. In particular, we focused on aliphatic hydroxylation of toluene and $\mathrm{CHD}$, and hydroxylation/dehydrogenation of $\mathrm{CHD}$ and epoxidation of $\mathrm{CHD}$. Toluene undergoes the expected HAT with a free energy of activation of $13.4 \mathrm{kcal} \mathrm{mol}^{-1}$ on the doublet spin state and 16.3

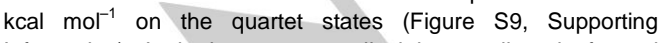
Information). In both cases a radical intermediate is formed representing $\left.\left[\mathrm{Fe}^{\mathrm{IV}}(\mathrm{OH})(\mathrm{TPFPP})\right]^{+}-\mathrm{C}_{7} \mathrm{H}_{7}{ }^{-}\right]$. However, it is expected its lifetime will be short as the reaction is completed with an $\mathrm{OH}^{*}$ rebound to form the final alcohol products with negligible barrier. Finally, the reaction of ${ }^{4,2}\left[\mathrm{Fe}^{\mathrm{IV}}(\mathrm{O})\left(\mathrm{TPFPP}^{+*}\right)\right]^{+}$with $\mathrm{CHD}$ was investigated computationally leading to either epoxidation, hydroxylation or dehydrogenation products. Interestingly, all reactions have very small barriers of less than $1.2 \mathrm{kcal} \mathrm{mol}^{-1}$ for concerted reaction mechanisms leading to products directly. As such, the reaction of ${ }^{4,2}\left[\mathrm{Fe}^{\mathrm{IV}}(\mathrm{O})\left(\mathrm{TPFPP}^{+*}\right)\right]^{+}$with $\mathrm{CHD}$ should lead to a mixture of products. This is surprising as $\mathrm{CHD}$ as a substrate with iron(IV)-oxo or manganese(V)-oxo complexes in solution typically gives dehydrogenation to benzene as the sole product. $^{[29]}$ Our gas-phase model, therefore, has properties significantly deviating from solution-based oxidants and consequently gives different reactivity patterns, which we analyze in detail below. Most probably the lack of an axial ligand in our $\left[\mathrm{Fe}^{\mathrm{IV}}(\mathrm{O})\left(\mathrm{TPFPP}^{+*}\right)\right]^{+}$model gives it significantly different chemical properties and results in reactivity differences.

\section{Discussion}

In order to understand the mechanistic details of the reaction pathways and find the origin of hydride versus hydrogen atom abstraction processes, we did a detailed analysis of the electronic and thermochemical properties of reactants and intermediates. Let us start with a look at the spin density distribution of reactant complexes and rate determining transition states, see Figure 4. As can be seen from the spin densities in the reactant complexes of $\left[\mathrm{Fe}^{\mathrm{IV}}(\mathrm{O})\left(\mathrm{Por}^{+*}\right)\right]^{+}$with $\mathrm{CHT}$, designated ${ }^{2,4} \mathbf{R e}$, there is considerable spin density found on the substrate moiety, i.e. $\rho_{\text {Sub }}=0.34(-0.42)$ in ${ }^{4} \mathbf{R e}\left({ }^{2} \mathbf{R e}\right)$, respectively. The systems with TPFPP as equatorial ligand give analogous spin density distributions, see Tables S11 and S12 (Supporting Information). Similar spin density distributions are also seen for the reactant complexes containing cyclohexadiene and toluene. Therefore, upon approach of the substrate to the iron(IV)-oxo species, a considerable charge transfer happens from the substrate to the porphyrin group, which thereby loses radical character. This type of charge transfer in the reactant complexes is not seen in similar iron(IV)-oxo complexes bearing an axial ligand. ${ }^{[18,25]}$ In one previous study ${ }^{[20 \mathrm{c}, 30]}$ of a nonheme iron(IV)-tosylimido complex with CHD also electron transfer in the reactant complexes was observed due to the large electron 
(a)

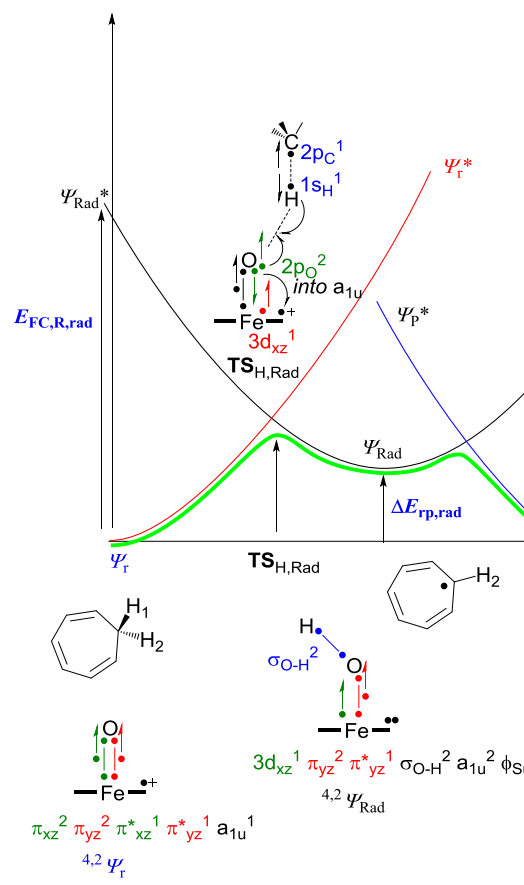

(b)

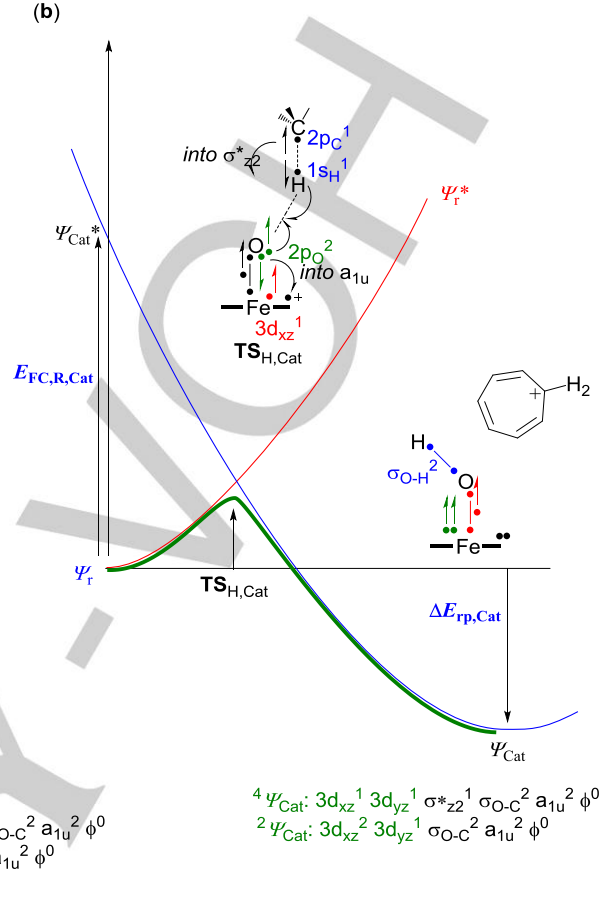

Figure 5. Valence bond curve crossing diagrams for a stepwise hydroxylation (a) and concerted hydroxylation (b) pathways. Dots represent electrons and a line in between two dots is a bonding orbital with two electrons.

The group spin densities of $\mathbf{T S}_{\mathrm{HA}, \mathrm{CHT}}$ and $\mathbf{T S}_{\mathrm{OAT}, \mathrm{CHT}}$ are also given in Figure 4 and display even more charge-transfer from substrate to porphyrin as compared to the reactant complexes. In particular, in ${ }^{4,2} \mathbf{T S}_{\mathrm{HA}, \mathrm{CHT}}$ a spin density of $\rho$ sub $=0.90(-0.73)$ is found for the quartet (doublet) spin state and hence almost a full electron transfer has taken place at this stage, so that the transition state corresponds to hydrogen atom abstraction. However, the subsequent intermediates IR1 for either the Por or TPFPP ligand systems have no radical on the substrate group, hence are cationic. Therefore, along the pathway from $\mathbf{T S}_{\mathrm{HA}}$ to IR1 an extra electron transfer has occurred to give an overall hydride transfer leading to the local minimum IR1. As such, even though IR1 mimics a hydride transfer local minimum, in fact the reaction proceeds via an initial hydrogen atom transfer in the transition state followed by a fast electron transfer en route to the intermediate IR1. Clearly, the hydride transfer is split into a hydrogen atom transfer followed by an electron transfer and these two processes are not simultaneous, namely the hydrogen atom transfer happens first, i.e. in the TS, and the subsequent electron transfer happens after the TS. As a result of this, the subsequent $\mathrm{OH}$ rebound will refer to an $\mathrm{OH}^{-}$transfer to the substrate cation. The early second electron transfer will lower the energy of the iron-hydroxo intermediate in the mechanism. As a matter of fact the energy of ${ }^{4,2} \mathbf{I R} \mathbf{1}$ is lower than that of the alcohol product complexes with a substantial rebound barrier in the low-spin state. It is, therefore, likely that $\mathrm{C}_{7} \mathrm{H}_{7}^{+}$will be released from IR1 as is also detected in the mass spectrum. The calculated mechanism and the obtained charge and spin distributions clearly support the experimental observations and explain the various product distributions.

To understand the obtained potential energy profiles and reaction mechanisms of the reaction of $\left[\mathrm{Fe}^{\mathrm{IV}}(\mathrm{O})\left(\mathrm{TPFPP}^{+*}\right)\right]^{+}$with $\mathrm{CHT}$ substrate, we set up a valence bond (VB) curve crossing diagram to gain insight into the electronic changes during the reaction. In the past, we used these valence bond diagrams to understand the electronic features of reactants that determine the transition states. Thus, we showed that in hydrogen atom abstraction transition states by metal(IV)-oxo oxidants, the rate determining barrier correlates with either the strength of the $\mathrm{C}-\mathrm{H}$ bond that is broken or the $\mathrm{O}-\mathrm{H}$ bond that is formed ${ }^{[18,25,31]}$ Furthermore, these VB diagrams explained the electronic origin of regioselectivities and bifurcation pathways. ${ }^{[20 \mathrm{~b}, 21,22,24 b, 32]}$ Note that in the following all calculations represent the large model as its thermochemistry was seen to be slightly different from the small model (compare Figures 2 and 3 ). The VB diagram explain the difference between stepwise and concerted reaction mechanisms and gives the various electron transfer processes 
and, in particular, highlights how hydrogen atom transfer and hydride transfer differ (Figure 5).

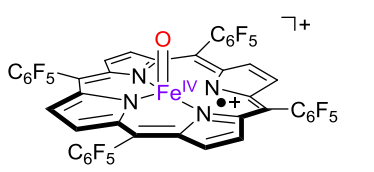

$\mathrm{EA}_{\mathrm{FeO}}=171.8(172.3)$<smiles>[C]1C=CC=CC=C1</smiles>

$\mathrm{CHT}$

$\mathrm{E}_{\mathrm{CHT}}=178$

$\mathrm{IE}_{\mathrm{CHT}}=178.4$

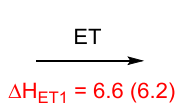

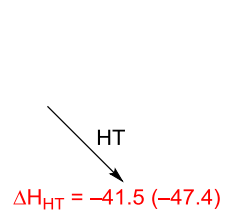

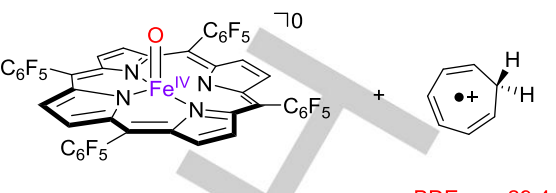

$\mathrm{BDE}_{\mathrm{CH}}=29.4$
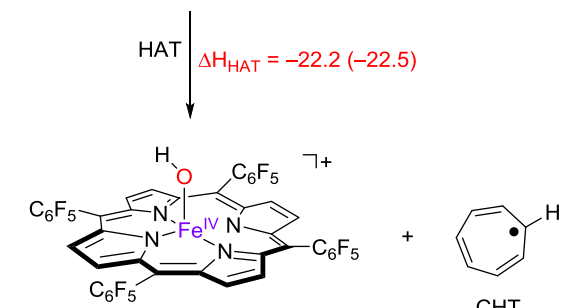

$\mathrm{BDE}_{\mathrm{OH}}=88.1(88.5)$

$\mathrm{CHT}$

$\mathrm{E}_{\mathrm{CHT} \text {-rad }}=141$.

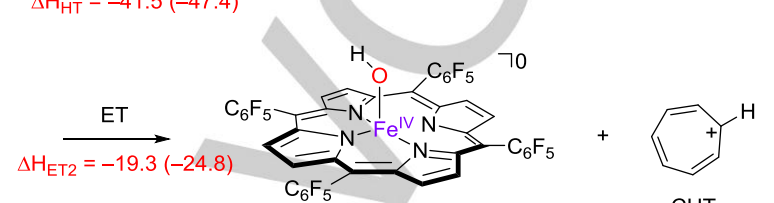

$\mathrm{BDE}_{\mathrm{OH}}=77.5(83.0)$

$\mathrm{EA}_{\mathrm{FeOH}}=161.3(166.8)$

Figure 6. Thermochemical reaction scheme for individual electron, proton and hydride transfer from iron(IV)-oxo and iron(IV)-hydroxo complexes. Data represent reaction enthalpies (in $\mathrm{kcal} \mathrm{mol}^{-1}$ ) as calculated at UB3LYP/BS2//UB3LYP/BS1 with ZPE corrections included. Quartet spin data in parenthesis, doublet spin data out of parenthesis.

Previously, a stepwise mechanism for substrate hydroxylation for aliphatic hydroxylation by $\mathrm{Cpdl}$ of P450 was reported with a VB landscape similar to the one shown on the left-hand-side of Figure $5 .{ }^{[25,31-33]}$ Thus, in VB theory the reactant configuration has wave function $\Psi_{\mathrm{r}}$ and connects to an excited state in the product geometry with wave function $\Psi_{\mathrm{r}}{ }^{*}$. The product wave function is $\Psi_{\mathrm{P}}$ in the product geometry and connects to an excited state in the reactant geometry with wave function $\Psi_{\mathrm{p}}{ }^{*}$.

The point where these two wave functions cross should lead to a transition state for the reaction. However, another wave function for the radical intermediate bifurcates these two curves and gives a local minimum with wave function $\Psi_{\text {Rad. }}$. As it happens, the first crossing point is between $\Psi_{\text {Rad }}$ and $\Psi_{r}$ is well lower in energy than the one between $\Psi_{\mathrm{r}}$ and $\Psi_{\mathrm{p}}$, hence the reaction proceeds via a preferred stepwise mechanism via a radical intermediate. Therefore, our analysis will be focused on the electronic configuration of reactants and products and how the electronic configuration of reactants needs to change to initiate the chemical reaction.

In our model the reaction starts from $\left[\mathrm{Fe}^{\mathrm{IV}}(\mathrm{O})\left(\mathrm{TPFPP}^{+*}\right)\right]^{+}$, which is an iron(IV)-oxo porphyrin cation radical species with orbital occupation $\pi_{x z}{ }^{2} \pi_{y z}{ }^{2} \pi^{*}{ }_{x z}{ }^{1} \pi^{*}{ }_{y z}{ }^{1} a_{1 u}{ }^{1}{ }^{[11]}$ Occupation of the $\pi_{x z}$ and $\pi^{*} x z$ orbitals with three electrons means there is a two-center three-electron bond located in the $\mathrm{xz}$-plane along the $\mathrm{Fe}-\mathrm{O}$ axis. In addition, there is another two-center three-electron bond in the yz-plane due to occupation of $\pi_{\mathrm{yz}}$ and $\pi_{\mathrm{yz}}^{*}$ with three electrons (shown in red in Figure 5). In addition, $\left[\mathrm{Fe}^{\mathrm{IV}}(\mathrm{O})\left(\mathrm{TPFPP}^{+*}\right)\right]^{+}$has a singly occupied orbital with $\mathrm{a}_{1 \mathrm{u}}$ symmetry on the porphyrin ligand. Upon activation of the substrate, a hydrogen atom abstraction transition state results in breaking of the $\sigma_{\mathrm{C}-\mathrm{H}}$ orbital in the substrate into atomic orbitals $\left(2 p_{\mathrm{C}}\right.$ and $\left.1 s_{H}\right)$. Furthermore, the $\pi_{\mathrm{xz}}{ }^{2} \pi^{*}{ }_{\mathrm{xz}}{ }^{1}$ pair of orbitals revert to atomic orbitals $2 \mathrm{p}_{\circ}{ }^{2} 3 \mathrm{~d}_{\mathrm{xz}}{ }^{1}$, whereby one electron from the $2 \mathrm{p}_{\mathrm{o}}$ orbital is promoted to the $a_{1 u}$ orbital. Finally, the remaining $2 p_{\circ}$ electron pairs up with the $1 \mathrm{~s}_{\mathrm{H}}$ electron to form the $\sigma_{\mathrm{O}-\mathrm{H}}$ orbital. Consequently, the hydrogen atom abstraction barrier $\left(\mathrm{E}_{\mathrm{TS}(\mathrm{H}, \mathrm{Rad})}\right)$ is determined by the strength of the $\mathrm{C}-\mathrm{H}$ bond that is broken $\left(\mathrm{BDE}_{\mathrm{CH}}\right)$, the strength of the $\mathrm{O}-\mathrm{H}$ bond that is formed $\left(\mathrm{BDE}_{\mathrm{OH}}\right)$, the strength of the $\pi_{x z} / \pi^{*}{ }_{x z}$ orbitals that are broken $\left(E_{\pi / \pi^{*} \times z}\right)$ and the excitation energy from $2 p_{0}$ to the porphyrin group $\left(E_{\text {exc }}\right)$, Eq $1^{[24 \mathrm{c}, 32]}$

$\mathrm{E}_{\mathrm{TS}(\mathrm{H}, \mathrm{Rad})} \propto \mathrm{BDE}_{\mathrm{CH}, \mathrm{CHT}}-\mathrm{BDE}_{\mathrm{OH}}+\mathrm{E}_{\pi / \pi^{*} \times \mathrm{z}}+\mathrm{E}_{\mathrm{exc}}$

In the concerted mechanism (Figure $5 b$ ) these same bond breaking and bond forming reactions occur. However, at the same time, an electron is promoted from the $2 p_{c}$ orbital of the $\mathrm{CHT}$ group into the metal-type orbitals, i.e. into the $\sigma^{*}{ }_{z 2}$ orbital in the quartet spin state and into $3 d_{x z}$ in the doublet spin state. Therefore, the barrier $\left(\mathrm{E}_{\mathrm{TS}(\mathrm{H}, \mathrm{Cat})}\right)$ for the concerted mechanism will be dependent on the energy to break the $\mathrm{C}-\mathrm{H}$ bond $\left(\mathrm{BDE}_{\mathrm{CH}}\right)$, the energy to form the $\mathrm{O}-\mathrm{H}$ bond $\left(\mathrm{BDE}_{\mathrm{OH}}\right)$, the energies to split the $\pi_{x z} / \pi_{x z}^{*}$ pair of orbitals into atomic orbitals $\left(\mathrm{E}_{\pi / \pi^{*} \times z}\right)$, the electron transfer from $2 p_{o, x}$ to $a_{1 u}\left(E_{e x c}\right)$ and from $2 p_{c}$ to $\sigma^{*}{ }_{z 2} / 3 d_{x z}$. The latter excitation refers to the ionization energy of $\mathrm{CHT}$ (IE $\left.\mathrm{E}_{\mathrm{Sub}}\right)$ and the electron affinity of the iron(IV)-oxo complex $\left(\mathrm{EA}_{\mathrm{FeO}}\right), \mathrm{Eq}$ 2 .

$\mathrm{E}_{\mathrm{TS}(\mathrm{H}, \mathrm{Cat})} \propto \mathrm{BDE}_{\mathrm{CH}, \mathrm{CHT}}-\mathrm{BDE}_{\mathrm{OH}}+\mathrm{E}_{\pi / \pi^{*} \mathrm{xz}}+\mathrm{E}_{\mathrm{exc}}+\mathrm{IE}_{\mathrm{Sub}}+\mathrm{EA}_{\mathrm{FeO}}$ (2)

Consequently, the VB analysis highlights the fundamental differences between hydrogen atom and hydride transfer processes. In particular, it shows that hydride transfer is only 
possible if the second electron transfer is an exothermic reaction. Therefore, the hydrogen atom abstraction barrier is always lower in energy than the hydride transfer barrier unless the energy difference between the ionization energy of the substrate ( $\mathrm{IE}_{\mathrm{Sub}}$ ) and the electron affinity of the oxidant $\mathrm{EA}_{\mathrm{FeO}}$ is negative. To find out if that is the case for substrates $\mathrm{CHT}, \mathrm{CHD}$ and toluene, we estimated values for all these individual contributions from adiabatic electron and hydrogen atom transfer energies or the molecular orbital differences in the reactant complexes.

Figure 6 gives the enthalpic differences for individual electron, hydrogen atom and hydride transfer processes from $\mathrm{CHT}$ to iron(IV)-oxo porphyrin cation radical. Thus, the reactions from left to right represent electron transfer to form $\left[\mathrm{Fe}^{\mathrm{IV}}(\mathrm{O})(\mathrm{TPFPP})\right]^{0}$ and $\mathrm{C}_{7} \mathrm{H}_{8}{ }^{+*}$ and has a small endothermic driving force of $\Delta \mathrm{H}_{\mathrm{ET}}=$ 6.6 (6.2) $\mathrm{kcal} \mathrm{mol}^{-1}$ in the doublet (quartet) spin states. Therefore, a long-range electron transfer between oxidant and substrate will not happen. Furthermore, the difference between radical and cationic pathways displayed in Figure 5 implicated that the radical pathway would be lower for an endothermic electron transfer. As this is the case, the combination of VB and thermochemical modelling predicts a rate-determining hydrogen atom abstraction first.

By contrast, the enthalpy of reaction for hydrogen atom abstraction is calculated as $\Delta \mathrm{H}_{\text {HAT }}=-22.2(-22.65) \mathrm{kcal} \mathrm{mol}^{-1}$ in the doublet (quartet) spin states. Consequently, approach of substrate on $\left[\mathrm{Fe}^{\mathrm{IV}}(\mathrm{O})\left(\mathrm{TPFPP}^{+*}\right)\right]^{+}$will lead to a hydrogen atom abstraction and the formation of $\left[\mathrm{Fe}^{\mathrm{IV}}(\mathrm{OH})(\mathrm{TPFPP})\right]^{+}$and $\mathrm{C}_{7} \mathrm{H}_{7}{ }^{\circ}$ rather than electron transfer. However, the electron transfer between $\left[\mathrm{Fe}^{\mathrm{IV}}(\mathrm{OH})(\mathrm{TPFPP})\right]^{+}$and $\mathrm{C}_{7} \mathrm{H}_{7}{ }^{\circ}$ has an exothermic driving force of $\Delta \mathrm{H}_{\mathrm{ET}}=-19.3(-24.8) \mathrm{kcal} \mathrm{mol}^{-1}$ for the doublet (quartet) pathways. This means that although no electron transfer will take place between reactants, as soon as the hydrogen atom transfer has taken place it becomes energetically feasible and will happen quickly.

Indeed, the DFT calculations reported above give a mechanism whereby an initial hydrogen atom abstraction took place followed by a fast electron transfer in an overall hydride transfer process. If we now calculate the reaction enthalpies for Figure 6 but with cyclohexadiene or toluene as a substrate, we find an analogous result, whereby the long-range electron transfer is energetically unfavorable over hydrogen atom transfer but by an even larger amount. In the case of cyclohexadiene, the electron transfer from $\mathrm{C}_{6} \mathrm{H}_{7}{ }^{+}$to $\left[\mathrm{Fe}^{\mathrm{IV}}(\mathrm{OH})(\mathrm{TPFPP})\right]^{+}$is still exothermic by $6.0 \mathrm{kcal}$ $\mathrm{mol}^{-1}$, while it is endothermic for toluene. Therefore, cyclohexadiene is expected to also react via an overall hydride transfer with an initial hydrogen atom abstraction followed by electron transfer, whereas no such electron transfer will be expected for toluene.

\section{Conclusions}

In this work a combined mass spectrometry and density functional theory study is presented on the reactivity of $\left[\mathrm{Fe}^{\mathrm{IV}}(\mathrm{O})\left(\mathrm{TPFPP}^{+*}\right)\right]^{+}$with $\mathrm{CHT}$ and selected substrates. We find a reaction mechanism whereby electron transfer is determined by the intermediate structure. Thus, although a formal hydride transfer is thermochemically favorable, actually the initial step is hydrogen atom transfer with a subsequent electron transfer. As such, hydride transfer processes should be seen as consecutive hydrogen atom and electron transfer processes, where an initial hydrogen atom abstraction is followed by a quick electron transfer as also reported previously for the reactivity of analogous heme and nonheme iron(IV)-oxo oxidants. Our thermochemical modelling shows that the original reactant cannot react via electron transfer as it is endothermic; however, the subsequent intermediate, namely the iron(IV)-hydroxo species, has a sufficiently large electron affinity to abstract electrons from the substrate. This mechanism may have relevance to enzymatic and biomimetic reactivity work where often hydride transfer processes are proposed and explains the intrinsic properties of substrate and oxidant that determines the reaction mechanism

\section{Experimental Section}

\section{Experiment.}

All chemicals and solvents were research grade products purchased from commercial sources and used as received. For the synthesis of the iron(IV)-oxo porphyrin cation radical complex, a reaction of $(5,10,15,20$ tetrakis(pentafluorophenyl)porphinato) iron(III) chloride, [Fe III(TPFPP)]Cl was applied with iodosylbenzene $\left(\mathrm{C}_{6} \mathrm{H}_{5} \mathrm{IO}\right)$, which was synthesized according to a literature procedure ${ }^{[34]}$ and stored at $-20{ }^{\circ} \mathrm{C}$. The cycloheptatriene-7-[ $\left[D_{1}\right]$ was prepared by the reduction of 7 acetoxynorbornadiene with $\mathrm{LiAID}_{4}$ in tetrahydrofuran as described in the literature. ${ }^{[35]}$ Subsequently, it was purified by preparative GLC using a 3 m column filled with Chromosorb 80/100 W-AW coated with a base deactivated polyethyleneglycol stationary phase, mounted on a Carlo Erba FRACTOVAP Mod ATC/f series 410 gas chromatograph. The identification, purity and deuterium content was obtained by GLC-MS analyses on a Hewlett-Packard 5890 gas chromatograph coupled with a model 5989B quadrupole mass spectrometer, by using a $50 \mathrm{~m}$ long, 0.2 $\mathrm{mm}$ i.d. fused silica capillary column, coated with cross-linked methylsilicone film. The extent of D-incorporation in cycloheptatriene-7$\left[D_{1}\right]$ was found equal to 98.0 atom $\% \mathrm{D}$.

\section{Instrumental.}

All procedures and methods follow those from our previous studies on these chemical systems. ${ }^{[11,12]}$ Mass spectrometric studies were performed on a Bruker BioApex Fourier transform-ion cyclotron resonance $(F T-I C R)$ mass spectrometer, which is implemented with a cylindrical infinity cell, a $4.7 \mathrm{~T}$ superconducting magnet and an Apollo I electrospray ionization (ESI) source. Analyte solutions were infused into the mass spectrometer at a continuous flow rate of $120 \mu \mathrm{L} \mathrm{h}^{-1}$ by a syringe pump through a $50 \mu \mathrm{m}$ i.d. fused-silica capillary. Subsequently, ions were desolvated by applying an $\mathrm{N}_{2}$ counter current of drying gas heated at $400 \mathrm{~K}$, trapped and accumulated in a radiofrequency-only hexapole ion guide for 0.8 seconds, and then pulsed into the ICR cell (held at room temperature, $300 \mathrm{~K}$ ). An ion ejection procedure was used to select the ions of interest, namely $\left[\mathrm{Fe}^{\mathrm{IV}}(\mathrm{O})\left(\mathrm{TPFPP}^{+*}\right)\right]^{+}$with $\mathrm{m} / \mathrm{z} 1044$, and their reactivity and fragmentation patterns were studied through ionmolecule reactions by inserting neutral collision gases to the ICR cell at stationary pressures (in the range $1.0-15 \times 10^{-8} \mathrm{mbar}$ ) by a needle valve. The product ion abundances were monitored as a function of time and analyzed. The pressure readings, obtained from a cold-cathode sensor (IKR Pfeiffer Balzers S.p.A., Milan, Italy), were calibrated against the rate constant of proton transfer from methane cation radical to methane, $\mathrm{Eq} 3$, for which the rate constant has been accurately determined at $\mathrm{k}=1.1 \times 10^{-9} \mathrm{~cm}^{3} \mathrm{~s}^{-1}$ and weighted by using individual response factors. ${ }^{[36]}$

$\mathrm{CH}_{4}^{++}+\mathrm{CH}_{4} \rightarrow \mathrm{CH}_{5}^{+}+\mathrm{CH}_{3}$ 
Rate constants for the reaction processes were derived from the ion abundance of the reactant ion, $\left[\mathrm{Fe}^{\mathrm{IV}}(\mathrm{O})\left(\mathrm{TPFPP}^{+}\right)\right]^{+}$, monitored as a function of time at each selected pressure. The slope of these semilogarithmic plots gave us the pseudo first-order rate constants for the disappearance of $\left[\mathrm{Fe}^{\mathrm{IV}}(\mathrm{O})\left(\mathrm{TPFPP}^{+*}\right)\right]^{+}$, then divided by the substrate concentration to obtain second-order rate constants $\left(\mathrm{k}_{\exp }\right)$ at $300 \mathrm{~K}$. All measurements were done at least in triplicate and averaged. Whereas the reproducibility of $\mathrm{k}_{\exp }$ values is within $10 \%$, the estimated error in the absolute rate constants is estimated to be $\pm 30 \%$. The ratio of the secondorder rate constant and the collision rate constant $\left(\mathrm{k}_{\mathrm{ADO}}\right)$, as described in Eq 4, enabled us to estimate the reaction efficiencies $(\Phi)$. Values for $k_{A D O}$ were calculated using the parametrized trajectory theory. ${ }^{[3]}$

$\Phi=k_{\text {exp }} / k_{A D O} \times 100 \%$

\section{Sample preparation.}

The $\left[\mathrm{Fe}^{\mathrm{IV}}(\mathrm{O})\left(\mathrm{TPFPP}^{+*}\right]^{+}\right.$ion was synthesized by adding iodosylbenzene $(0.5 \mathrm{mM})$ to $10 \mu \mathrm{M}$ of [Fe $\left.\mathrm{Fe}^{\text {III }}(\mathrm{TPFPP})\right] \mathrm{Cl}$ in a methanol/dichloromethane $(1: 1)$ mixture and was stable for about $1 \mathrm{~h}$, if kept cooled at $-40^{\circ} \mathrm{C}$. The high-resolution ESI FT-ICR mass analysis of the reaction mixture gave a prominent peak centered at $\mathrm{m} / \mathrm{z} 1044$ with isotopic pattern conforming to an iron(IV)-oxo complex, $\left[\mathrm{Fe}^{\mathrm{IV}}(\mathrm{O})\left(\mathrm{TPFPP}^{+*}\right)\right]^{+}$, as well as a signal for the reduced form [Fell'(TPFPP) $]^{+}$at $\mathrm{m} / \mathrm{z}$ 1028. As already described in reduced form [Fe $(\mathrm{TPFPP})]^{+}$at $\mathrm{m} / \mathrm{z}$ 1028. As already described in
previous contributions, ${ }^{[10 a, 11,12]}$ the synthetic procedure leads to the formation of an additional fraction of isomeric species, most likely corresponding to a four-coordinate iron(III) complex oxidized on the porphyrin ring and unable to perform any oxidation reactions. This portion, quantified by its complete trapping by NO gives the [Fe"ll'(TPFPP$\mathrm{O})(\mathrm{NO})]^{+}$adduct, similarly to the reduced form, $\left[\mathrm{Fe}^{\mathrm{III}}(\mathrm{TPFPP})\right]^{+}$, and was discarded from the kinetic analysis.

\section{Density functional theory modelling}

Calculations were done using density functional theory methods as implemented in Gaussian-09, ${ }^{[38]}$ and follow methods and procedures as reported and tested previously on analogous complexes and reactions. ${ }^{[20,39]}$ In general, the unrestricted B BLYP hybrid density functional theory is used for all geometry optimizations and frequencies. ${ }^{[40]}$ All structures were optimized in the gas phase with an frequencies. All stuctures were optimized in the gas phase with an the atoms $(\mathrm{H}, \mathrm{C}, \mathrm{N}, \mathrm{O})$ : basis set $\mathrm{BS} 1{ }^{\left[{ }^{[41]}\right.}$ Single points using a triple- $\zeta$ quality basis set on iron (with core potential), i.e. LACV3P+, and 6$311+G^{*}$ on the rest of the atoms were done to correct the energies: basis set BS2. All stationary points had real frequencies and transition states were characterized with a single imaginary frequency for the correct mode. Energies reported here are UB3LYP/BS2//UB3LYP/BS1 with zeropoint energy included. Previous studies showed little differences in optimized geometries and reaction kinetics between geometry optimizations at UB3LYP/BS2 and UB3LYP/BS1 level of theory, ${ }^{[11,12]}$ hence the latter was used here.

Kinetic isotope effects are calculated from the free energy of activation difference between hydrogen atom abstraction transition state and isolated reactants $\left(\Delta \mathrm{G}^{\mp}{ }_{\mathrm{HA}}\right)$ between the substrate with all hydrogen atoms and the one with one or more hydrogen atoms replaced by deuterium, according to $\mathrm{Eq}, 5$, with $\mathrm{R}$ being the gas constant and $\mathrm{T}$ the estimated temperature $(300 \mathrm{~K}){ }^{[42]}$

$\mathrm{KIE}=\exp \left(\left(\Delta \mathrm{G}^{\ddagger}{ }_{\mathrm{HA}, \mathrm{D}}-\Delta \mathrm{G}_{\mathrm{HA,H}}^{\ddagger}\right) / \mathrm{RT}\right)$

Acknowledgements
FGCR thanks the Conacyt Mexico for a studentship. The COST Action (CM1305 ECOSTBio, Explicit Control Over Spin-States in Technology and Biochemistry) is acknowledged for support.

Keywords: High-valent iron(IV)-oxo • Porphyrin • density functional theory $\cdot$ FT-ICR MS $\cdot$ reaction mechanisms

[1] a) M. Sono, M. P. Roach, E. D. Coulter, J. H. Dawson, Chem. Rev. 1996, 96, 2841-2888; b) J. T. Groves, Proc. Natl. Acad. Sci. USA, 2003 100, 3569-3574; c) Ed.: P. R. Ortiz de Montellano, Cytochrome P450: Structure, Mechanism and Biochemistry, $3^{\text {rd }}$ ed., Kluwer Academic / Plenum Publishers, New York, 2005; d) P. R. Ortiz de Montellano, Chem. Rev. 2010, 110, 932-948; e) Eds.: K. M. Kadish, K. M. Smith, R. Guilard, Handbook of Porphyrin Science, World Scientific Publishing Co., New Jersey, 2010

[2] a) D. R. Nelson, Human Genomics 2009, 4, 59-65; b) F. P. Guengerich, Chem. Res. Toxicol. 2001, 14, 611-650; c) T. L. Poulos, Chem. Rev. 2014, 114, 3919-3962.

[3] a) B. Meunier, S. P. de Visser, S. Shaik, Chem. Rev. 2004, 104, 39473980; b) I. G. Denisov, T. M. Makris, S. G. Sligar, I. Schlichting, Chem. Rev. 2005, 105, 2253-2278; c) J. Rittle, M. T. Green, Science 2010 330, 933-937.

[4] a) W. Nam, Acc. Chem. Res. 2007, 40, 522-531; b) Y. Watanabe, H. Nakajima, T. Ueno, Acc. Chem. Res. 2007, 40, 554-562.

[5] a) W. Nam, Y.-M. Lee, S. Fukuzumi, Acc. Chem. Res. 2014, 47, 11461154; b) M. Asaka, H. Fujii, J. Am. Chem. Soc. 2016, 138, 8048-8051; c) L. Ji, A. Franke, M. Brindell, M. Oszajca, A. Zahl, R. van Eldik, Chem Eur. J. 2014, 20, 14437-14450.

[6] a) F. Ogliaro, N. Harris, S. Cohen, M. Filatov, S. P. de Visser, S. Shaik, J. Am. Chem. Soc. 2000, 122, 8977-8989; b) S. Shaik, D. Kumar, S. P. de Visser, A. Altun, W. Thiel, Chem. Rev. 2005, 105, 2279-2328; c) D. Li, Y. Wang, K. Han, Coord. Chem. Rev. 2012, 256, 1137-1150; d) M. R. A. Blomberg, T. Borowski, F. Himo, R.-Z. Liao, P. E. M. Siegbahn, Chem. Rev. 2014, 114, 3601-3658.

[7] a) Y. J. Jeong, Y. Kang, A. R. Han, Y. M. Lee, H. Kotani, S. Fukuzumi, W. Nam, Angew. Chem. Int. Ed. 2008, 47, 7321-7324; b) S. Fukuzumi, H. Kotani, Y.-M. Lee, W. Nam, J. Am. Chem. Soc. 2008, 130, 1513415142 .

[8] L. Tahsini, M. Bagherzadeh, W. Nam, S. P. de Visser, Inorg. Chem 2009, 48, 6661-666.

M. E. Crestoni, S. Fornarini, F. Lanucara, Chem. Eur. J. 2009, 15, 7863-7866.

[10] a) R. Chiavarino, R. Cipollini, M. E. Crestoni, S. Fornarini, F. Lanucara, A. Lapi, J. Am. Chem. Soc. 2008, 130, 3208-3217; b) M. E. Crestoni, S. Fornarini, Inorg. Chem. 2007, 46, 9018-9020; c) M. E. Crestoni, S. Fornarini, Inorg. Chem. 2005, 44, 5379-5387.

[11] M. A. Sainna, S. Kumar, D. Kumar, S. Fornarini, M. E. Crestoni, S. P. de Visser, Chem. Sci. 2015, 6, 1516-1529.

[12] F. G. Cantú Reinhard, M. A. Sainna, P. Upadhyay, G. A. Balan, D. Kumar, S. Fornarini, M. E. Crestoni, S. P. de Visser, Chem. Eur. J. 2016, 22, 18608-18619.

[13] E. P. Hunter, S. G. Lias, NIST Chemistry Webbook, NIST Standard Reference Database, Number 69; Eds.: P. J. Linstrom, W. G. Mallard, National Institute of Standards and Technology: Gaithersburg MD, 20899, (retrieved June 7, 2017), http://webbook.nist.gov.

[14] Ed.: D. R. Lide, CRC Handbook of Chemistry and Physics, $90^{\text {th }}$ Ed. Internet Version 2010

[15] a) T. Shono, T. Nozoe, H. Maekawa, Y. Yamaguchi, S. Kanetaka, $H$. Masuda, T. Okada, S. Kashimura, Tetrahedron 1991, 47, 593-603; b) D. Jacobi, W. Abraham, U. Pischel, L. Gubert, R. Stösser, W. Schnabel, J. Chem. Soc. Perkin Trans. 2 1999, 1695-1702; c) Y. Xu, C. R. Johnson, Tetrahedron Lett. 1997, 38, 1117-1120.

[16] O. Krechkivska, C. Wilcox, G. D. O'Connor, K. Nauta, S. H. Kable, T. W. Schmidt, J. Phys. Chem. A 2014, 118, 10252-10258.

[17] a) D. Kumar, L. Tahsini, S. P. de Visser, H. Y. Kang, S. J. Kim, W. Nam, J. Phys. Chem. A 2009, 113, 11713-11722; b) R. Latifi, M. A. Sainna, E. V. Rybak-Akimova, S.. P. de Visser, Chem. Eur. J. 2013, 19, 40584068 . 
[18] a) S. P. de Visser, D. Kumar, S. Cohen, R. Shacham, S. Shaik, J. Am. Chem. Soc. 2004, 126, 8362-8363; b) R. Latifi, J. S. Valentine, W. Nam, S. P. de Visser, Chem. Commun. 2012, 48, 3491-3493.

[19] More exptl refs? a) B. Chiavarino, M. E. Crestoni, S. Fornarini, F. Lanucara, Eur. J. Mass Spectrom. 2010, 7, 407-414. b) F. Lanucara, M. E. Crestoni, Chem. Eur. J. 2011, 17, 12092-12100.

[20] a) F. G. Cantú Reinhard, A. S. Faponle, S. P. de Visser, J. Phys. Chem. A 2016, 120, 9805-9814; b) T. Yang, M. G. Quesne, H. M. Neu, F. G. Cantú Reinhard, D. P. Goldberg, S. P. de Visser, J. Am. Chem. Soc. 2016, 138, 12375-12386; c) A. K. Vardhaman, P. Barman, S. Kumar, C. V. Sastri, D. Kumar, S. P. de Visser, Angew. Chem. Int. Ed. 2013, 52, 12288-12292.

[21] a) A. Timmins, M. Saint-André, S. P. de Visser, J. Am. Chem. Soc. 2017, 139, 9855-9866; b) A. Timmins, S. P. de Visser, Frontiers Chem. 2017, 5, Article 94, pp 1-13.

[22] A. S. Faponle, M. G. Quesne, S. P. de Visser, Chem. Eur. J. 2016, 22, 5478-5483.

[23] a) M. T. Green, J. Am. Chem. Soc. 1999, 121, 7939-7940; b) S. P. de Visser, S. Shaik, P. K. Sharma, D. Kumar, W. Thiel, J. Am. Chem. Soc. 2003, 125, 15779-15788; c) S. P. de Visser, L. S. Tan, J. Am. Chem. Soc. 2008, 130, 12961-12974; d) F. G. Cantú Reinhard, S. P. de Visser, Inorganics 2017, 5, Article 77, pp 1-18.

[24] a) Y. Wang, D. Kumar, C. L. Yang, K. Han, S. Shaik, J. Phys. Chem. B 2007, 111, 7700-7710; b) L. Ji, A. S. Faponle, M. G. Quesne, M. A. Sainna, J. Zhang, A. Franke, D. Kumar, R. van Eldik, W. Liu, S. P. de Visser, Chem. Eur. J. 2015, 21, 9083-9092; c) F. G. Cantú Reinhard, S. P. de Visser, Chem. Eur. J. 2017, 23, 2935-2944.

[25] a) S. Shaik, D. Kumar, S. P. de Visser, J. Am. Chem. Soc. 2008, 130, 10128-10140; b) R. Latifi, M. Bagherzadeh, S. P. de Visser, Chem. Eur. J. 2009, 15, 6651-6662

[26] a) M. G. Quesne, D. Senthilnathan, D. Singh, D. Kumar, P. Maldivi, A. B. Sorokin, S. P. de Visser, ACS Catal. 2016, 6, 2230-2243; b) P. Barman, P. Upadhyay, A. S. Faponle, J. Kumar, S. S. Nag, D. Kumar, C. V. Sastri, S. P. de Visser, Angew. Chem. Int. Ed. 2016, 55, C. V. Sastri,

[27] a) M. M. Abu-Omar, A. Loaiza, N. Hontzeas, Chem. Rev. 2005, 105, 2227-2252; b) M. Atanasov, P. Comba, S. Hausberg, B. Martin, Coord. Chem. Rev. 2009, 253, 2306-2314; c) P. C. A. Bruijnincx, G. van Koten, R. J. M. Klein Gebbink, Chem. Soc. Rev. 2008, 37, 2716-2744; d) M. R. J. M. Klein Gebbink, Chem. Soc. Rev. 2008, 37, 2716-2744; d) M.
Costas, M. P. Mehn, M. P. Jensen, L. Que, Jr., Chem. Rev. 2004, 104, 939-986.

[28] S. P. de Visser, S. Shaik, J. Am. Chem. Soc. 2003, 125, 7413-7424.
[29] a) W. J. Song, Y. J. Sun, S. K. Choi, W. Nam, Chem. Eur. J. 2006, 12, 130-137; b) K. A. Prokop, S. P. de Visser, D. P. Goldberg, Angew. Chem. Int. Ed. 2010, 49, 5091-5095.

[30] S. Kumar, A. S. Faponle, P. Barman, A. K. Vardhaman, C. V. Sastri, D. Kumar, S. P. de Visser, J. Am. Chem. Soc. 2014, 136, 17102-17115.

[31] S. P. de Visser, J. Am. Chem. Soc. 2010, 132, 1087-1097

[32] X.-X. Li, V. Postils, W. Sun, A. S. Faponle, M. Solà, Y. Wang, W. Nam, S. P. de Visser, Chem. Eur. J. 2017, 23, 6406-6418.

[33] A. Hernández-Ortega, M. G. Quesne, S. Bui, D. J. Heyes, R. A. Steiner, N. S. Scrutton, S. P. de Visser, J. Am. Chem. Soc. 2015, 137, 74747487.

[34] H. Saltzman, J. G. Sharefkin, Organic Syntheses, Wiley, New York, 1973, Collect. Vol. 5, p 658.

[35] B. Franzus, E. I. Snyder, J. Am. Chem. Soc. 1963, 85, 3902-3903.

[36] a) M. Meot-Ner, In Gas Phase Ion Chemistry, Ed. M. T. Bowers, Academic Press, New York, 1979; Vol. 1; b) J. E. Bartmess, R. M. Georgiadis, Vacuum 1983, 33, 149-154.

[37] T. Su, W. J. Chesnavich, J. Chem. Phys. 1982, 76, 5183-5185.

[38] Gaussian-09, Revision C.01, M. J. Frisch, G. W. Trucks, H. B. Schlegel, G. E. Scuseria, M. A. Robb, J. R. Cheeseman, G. Scalmani, V. Barone, B. Mennucci, G. A. Petersson, H. Nakatsuji, M. Caricato, X. Li, H. P. Hratchian, A. F. Izmaylov, J. Bloino, G. Zheng, J. L. Sonnenberg, M. Hada, M. Ehara, K. Toyota, R. Fukuda, J. Hasegawa, M. Ishida, T. Nakajima, Y. Honda, O. Kitao, H. Nakai, T. Vreven, J. A. Montgomery, Jr., J. E. Peralta, F. Ogliaro, M. Bearpark, J. J. Heyd, E. Brothers, K. N. Kudin, V. N. Staroverov, T. Keith, R. Kobayashi, J. Normand, K Raghavachari, A. Rendell, J. C. Burant, S. S. Iyengar, J. Tomasi, M. Cossi, N. Rega, J. M. Millam, M. Klene, J. E. Knox, J. B. Cross, V. Bakken, C. Adamo, J. Jaramillo, R. Gomperts, R. E. Stratmann, O. Yazyev, A. J. Austin, R. Cammi, C. Pomelli, J. W. Ochterski, R. L. Martin, K. Morokuma, V. G. Zakrzewski, G. A. Voth, P. Salvador, J. J. Dannenberg, S. Dapprich, A. D. Daniels, O. Farkas, J. B. Foresman, J. V. Ortiz, J. Cioslowski, D. J. Fox, Gaussian, Inc., Wallingford CT, 2010.

[39] F. G. Cantú Reinhard, P. Barman, G. Mukherjee, J. Kumar, D. Kumar, D. Kumar, C. V. Sastri, S. P. de Visser, J. Am. Chem. Soc. 2017, 139, 18328-18338.

[40] a) A. D. Becke, J. Chem. Phys. 1993, 98, 5648-5652; b) C. Lee, W. Yang, R. G. Parr, Phys. Rev. B 1988, 37, 785-789.

[41] P. J. Hay, W. R. Wadt, J. Chem. Phys. 1985, 82, 270-283

[42] a) D. Kumar, S. P. de Visser, P. K. Sharma, S. Cohen, S. Shaik, J. Am. a) D. Kumar, S. P. de Visser, P. K. Sharma, S. Cohen, S. Shaik, J. Am.
Chem. Soc. 2004, 126, 1907-1920; b) S. P. de Visser, Chem. Eur. J. 2006, 12, 8168-8177. 
Entry for the Table of Contents

\section{FULL PAPER}

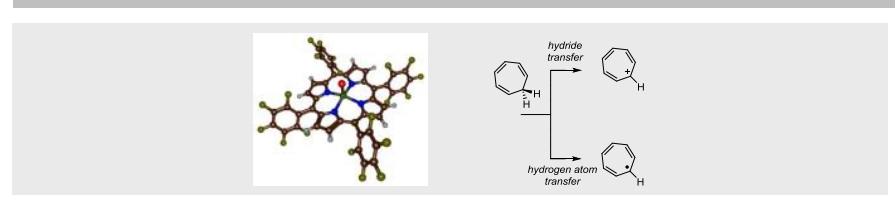

A combined mass spectrometry and computational study highlights the substrate and oxidant specificities that determine hydride transfer and hydrogen atom transfer mechanisms to cytochrome P450 Compound I models. The bifurcation pathways are further elucidated through thermochemical and valence bond modelling.
Fabián G. Cantú Reinhard, Simonetta Fornarini, * Maria Elisa Crestoni, ${ }^{*}$ and Sam P. de Visser*

Page No. - Page No.

Hydrogen atom versus hydride transfer in cytochrome P450 oxidations: A combined mass spectrometry and computational study 